\title{
Bladder cancer in women: a Sri Lankan study
}

\section{Serozsha AS Goonewardena1, Umesh Jayarajah', M V Chandu de Silva², Sanka N Kuruppu", D M Hilary Fernando', Kasun B Herath ${ }^{1}$}

(Index words: female bladder cancer, clinicopathological characteristics, Sri Lanka)

\begin{abstract}
Introduction Bladder cancer (BC) is the ninth commonest cancer globally, and ranks $19^{\text {th }}$ among women. The literature on $\mathrm{BC}$ in women is sparse, and the knowledge on the variations of tumour characteristics in South Asian female BC is limited. The objective of this study was to describe the clinicopathological characteristics of $\mathrm{BC}$ in women and compare them with male BC.

Methods A retrospective analysis of all female patients with histopathologically proven newly diagnosed primary BC from January 2007 to January 2017 was done at the Urology Unit, National Hospital of Sri Lanka, and the findings were compared with men with $\mathrm{BC}$ during the same period.
\end{abstract}

Results There were 314 patients with primary BC, of which $55(17.5 \%)$ were women, with a male:female ratio of 4.7:1. Only $70.9 \%$ of women had haematuria at presentation. Forty-four women $(80 \%)$ had urothelial bladder cancers (UBC). The mean age of women with UBC was $67 \pm S D 13.2$ years, and for non-urothelial bladder cancers(NUBC) was $62.5 \pm S D 12.7$ years. NUBC in women accounted for a disproportionately higher percentage in comparison to men (20\% vs.5.4\%, $\mathrm{p}<0.001)$. Of the UBCs, muscle invasive BC accounted for $45.5 \%(20 / 44)$ in women as opposed to $33.5 \%$ $(82 / 245)$ in men. Women had a significantly higher proportion of solid tumours (40\%vs.22.8\%, $\mathrm{p}=0.008$ ) compared to men.

Conclusion Primary BC in women has a significantly higher proportion of NUBC and muscle invasive UBC, which are more aggressive cancers, compared to men. Furthermore, the lack of haematuria in $>25 \%$, and higher incidental diagnosis, with inherently thinner bladder wall, makes primary $\mathrm{BC}$ in women more likely to present late, in a more advanced state.

Ceylon Medical Journal 2019; 64: 98-102

DOI: http://doi.org/10.4038/cmj.v64i3.8952

\section{Introduction}

Bladder cancer is one of the most common malignancies worldwide [1]. It is the ninth most common cause of cancer for both sexes combined. Bladder cancer is relatively more common in more developed regions, where around $60 \%$ of all incident cases occur [1]. Urothelial bladder cancer (UBC) accounts for $>90 \%$ of primary BC in Sri Lanka with a male preponderance (male:female ratio of 6:1) [2]. While men are at a higher risk than women for developing UBC, women present with more advanced disease [3, 4].

Gender specific variations in the incidence, diagnosis and survival have been reported in several malignancies, such as lung, colorectal and head and neck cancer. These variations were found to be significant and thus have resulted in implementation of gender-specific recommendations in clinical oncology [5]. Similarly, gender specific variations were also described in bladder cancer. Compared with women, men are at a 3.5-fold higher risk of developing bladder cancer. In Sri Lanka, it is reported to be much higher, with a male to female ratio of $5.6: 1[1,2]$. Furthermore, a $25 \%$ faster increase in incidence was noted in men compared to women during the past decade [6]. Despite the commoner occurrence and increasing incidence in men, there is increasing evidence to suggest that women present with more aggressive cancers and advanced disease stages, and thus experience worse outcomes [7]. In most cancers of the head and neck, oesophagus, stomach, liver and pancreas, the risk of death for women is significantly lower. For bladder cancer, the risk of death is significantly greater for women [8].

Although it is well established that men are more greatly affected by bladder cancer, there is limited data in ${ }^{1}$ Department of Urology, National Hospital of Sri Lanka, Colombo, Sri Lanka, ${ }^{2}$ Department of Pathology, Faculty of
Medicine, University of Colombo, Sri Lanka.

Correspondence: SASG, e-mail: <drsasgurol@yahoo.com>. Received 28 April 2019 and revised version 8 July 2019 accepted 24 September 2019. 
terms of other biological tumour differences in women including grade, stage, location, and recurrence compared with men, particularly in the South Asian region. This retrospective analysis was aimed at describing the biological tumour characteristics in females while eliciting the differences compared with male bladder cancers

\section{Methods}

This is a retrospective analysis. All patients with newly diagnosed bladder cancer with histological confirmation at one of two Urology Units of National Hospital of Sri Lanka, Colombo, between January 2007 and January 2017 (over 10 year period) were analysed.

All patients underwent transurethral resection of the bladder tumour (TURBT) which is the standard procedure in the initial diagnosis and treatment of bladder cancer. In cases of papillary tumours and superficial solid tumours, every attempt was taken to perform a complete resection of the tumour during the first surgery. In cases of invasive solid tumours, the treatment was generous debulking of the exophytic component followed by radical therapy which includes chemoradiation or cystectomy. Data were collected at the time of hospital discharge/clinic visit on a separate file for each patient, rendering accurate documentation and easy retrieval of details. The clinical, cystoscopy and histopathological findings, such as tumour type, staging, grading and location were entered into the database. Tumours other than primary bladder cancers were excluded after initial evaluation. Pathological grading was assessed according to the World Health Organisation (WHO) and International Society of Urological Pathology (ISUP) classification 2004 [9]. Tumours were staged according to TNM classification: pTa $=$ non-invasive papillary carcinomas, $\mathrm{pT} 1=$ tumours that invade sub-epithelial connective tissues and pT2 = muscle-invasive tumours [10].

Data were analysed using SPSS ${ }^{\circledR}$ software version 17 and were expressed in terms of frequency and percentages. The mean with standard deviation (SD) was calculated for continuous variables, whereas frequencies and percentages were used for discrete data. Comparisons between groups were conducted by using the t-test or chi-square test as appropriate. A p $<0.05$ was considered statistically significant. Approval for the study was obtained from the Ethics Committee of National Hospital of Sri Lanka.

\section{Results}

There were 314 patients with primary BC of which 55 $(17.5 \%)$ were women with a male:female ratio of $4.7: 1$. Fortyfour women $(80 \%)$ had urothelial bladder cancers (UBC). Non-urothelial bladder cancers (NUBC) in women accounted for a disproportionately higher percentage in comparison to men $(20 \%$ vs. $5.4 \%, \mathrm{p}<0.001)$. The mean age of women with UBC was 67 \pm SD 13.2 years and for NUBC was $62.5 \pm \mathrm{SD} 12.7$ years. Overall, female patients were diagnosed at a mean age of $65.2 \pm$ SD 12.6 years which was comparable with males (65.2 \pm SD 11.1 years).

Considerable differences in the clinical presentation between genders were noted. Visible haematuria was the commonest presentation seen in females $(70.9 \%, \mathrm{n}=39)$. However, the proportion of females who presented with haematuria were significantly lower compared with males (70.9\% vs. $89.6 \%, \mathrm{p}<0.001)$. The mean duration of haematuria was 3.6 months which was greater than that of males. However, the difference was not statistically significant. The proportion of females with incidental finding of bladder cancer was significantly higher compared with males (20\% vs. $8.9 \%, \mathrm{p}=0.016)$ Table 1.

Table 1. Comparison of clinical parameters between the two sexes

\begin{tabular}{|c|c|c|c|c|c|c|}
\hline & \multicolumn{2}{|c|}{ Male } & \multicolumn{2}{|c|}{ Female } & \multirow{2}{*}{$\begin{array}{l}\text { Odds ratio } \\
(95 \% \text { CI })\end{array}$} & \multirow[t]{2}{*}{$p$ value } \\
\hline & N/ Mean & $\% / S D$ & N/ Mean & $\% / S D$ & & \\
\hline Age & $65.21 \pm$ SD 11.12 & $65.20 \pm$ SD 12.59 & - & - & & 1.00 \\
\hline Haematuria & 232 & 89.6 & 39 & 70.9 & $3.5(1.7-7.1)$ & $<0.001$ \\
\hline Duration of haematuria & $2.35 \pm \mathrm{SD} 4.04$ & $3.63 \pm$ SD 6.53 & - & - & & 0.10 \\
\hline Supra pubic pain & 22 & 8.5 & 5 & 9.1 & $0.9(0.3-2.6)$ & 0.886 \\
\hline Loin pain & 14 & 5.4 & 2 & 3.6 & $1.5(0.3-6.9)$ & 0.588 \\
\hline Incidental & 23 & 8.9 & 11 & 20.0 & $0.4(0.2-0.85)$ & 0.016 \\
\hline
\end{tabular}

CI: Confidence interval

Around $58 \%$ of females had tumours $>3 \mathrm{~cm}$ in diameter. Around $82 \%(\mathrm{n}=45)$ of tumours in females were solitary tumours whereas in males, $67.2 \%$ were solitary tumours $(\mathrm{p}=0.032)$. In females, the majority were papillary tumours $(47.3 \%)$, followed by solid tumours (40\%) and papillary with solid components (12.7\%). Compared with males, females had a significantly higher proportion of solid tumours (males vs. females: $22.8 \%$ vs. $40 \%, \mathrm{p}=0.008$ ) (Table 2). 
Table 2. Comparison of cystoscopy findings in the two sexes

\begin{tabular}{|c|c|c|c|c|c|c|c|}
\hline & & \multicolumn{2}{|c|}{ Male } & \multicolumn{2}{|c|}{ Female } & \multirow{2}{*}{$\begin{array}{c}\text { Odds ratio } \\
(95 \% \text { CI) }\end{array}$} & \multirow[t]{2}{*}{$p$ value } \\
\hline & & $N$ & $\%$ & $N$ & $\%$ & & \\
\hline \multirow[t]{2}{*}{ Size } & $<3 \mathrm{~cm}$ & 93 & 35.9 & 23 & 41.8 & $0.8(0.4-1.4)$ & 0.409 \\
\hline & $>3 \mathrm{~cm}$ & 166 & 64.1 & 32 & 58.2 & & \\
\hline \multirow[t]{4}{*}{ Multiplicity } & 1 & 174 & 67.2 & 45 & 81.8 & - & 0.197 \\
\hline & 2 & 40 & 15.4 & 5 & 9.1 & & \\
\hline & 3 & 21 & 8.1 & 2 & 3.6 & & \\
\hline & $>3$ & 24 & 9.3 & 3 & 5.5 & & \\
\hline \multirow[t]{2}{*}{ Focality } & Solitary & 174 & 67.2 & 45 & 81.8 & $0.5(0.2-0.9)$ & 0.032 \\
\hline & Multiple & 85 & 32.8 & 10 & 18.2 & & \\
\hline \multirow[t]{3}{*}{ Tumour morphology } & Papillary & 139 & 53.7 & 26 & 47.3 & - & 0.018 \\
\hline & Solid & 59 & 22.8 & 22 & 40.0 & & \\
\hline & $\begin{array}{l}\text { Papillary with } \\
\text { solid components }\end{array}$ & 61 & 23.6 & 7 & 12.7 & & \\
\hline \multirow[t]{2}{*}{ Solid vs. Papillary } & Solid & 59 & 22.8 & 22 & 40.0 & $0.4(0.2-0.8)$ & 0.008 \\
\hline & Papillary & 200 & 77.2 & 33 & 60.0 & & \\
\hline
\end{tabular}

CI: Confidence interval

Females had significantly higher muscle-invasive tumors ( $\mathrm{n}=29,52.7 \%)$ compared with males $(\mathrm{n}=88,34.0 \%)(\mathrm{p}=0.009)$. This was also the case in the UBC subgroup where females had higher proportion of muscle invasive tumours $(\mathrm{n}=20$, $45.5 \%)$ compared with males $(\mathrm{n}=82,33.5 \%)$, however it was not statistically significant $(\mathrm{p}=0.13)$. The proportion of lymphovascular invasion and pT1 high grade tumours were comparable in both sexes (Table 3 ).

Table 3. Comparison of histopathological features between the two sexes

\begin{tabular}{|c|c|c|c|c|c|c|c|}
\hline & & \multicolumn{2}{|c|}{ Male } & \multicolumn{2}{|r|}{ Female } & \multirow{2}{*}{$\begin{array}{l}\text { Odds ratio } \\
(95 \% \text { CI })\end{array}$} & \multirow[t]{2}{*}{$p$ value } \\
\hline & & $N$ & $\%$ & $N$ & $\%$ & & \\
\hline \multirow[t]{2}{*}{ Tumour type } & $\mathrm{UBC}$ & 245 & 94.6 & 44 & 80.0 & $4.4(1.9-10.3)$ & $<0.001$ \\
\hline & NUBC & 14 & 5.4 & 11 & 20.0 & & \\
\hline \multirow[t]{3}{*}{$\begin{array}{l}\text { Tumour stage } \\
\text { (All tumours) }\end{array}$} & $\mathrm{pTa}$ & 77 & 29.7 & 11 & 20.0 & - & 0.032 \\
\hline & p T 1 & 94 & 36.3 & 15 & 27.3 & & \\
\hline & pT 2 & 88 & 34.0 & 29 & 52.7 & & \\
\hline \multirow{2}{*}{$\begin{array}{l}\text { Muscle invasiveness } \\
\text { (All tumours) }\end{array}$} & MIBC & 88 & 34.0 & 29 & 52.7 & $0.5(0.3-0.8)$ & 0.009 \\
\hline & NMIBC & 171 & 66.0 & 26 & 47.3 & & \\
\hline $\begin{array}{l}\text { Presence of LVI } \\
\text { (All tumours) }\end{array}$ & 17 & 6.6 & 3 & 5.5 & $1.2(0.3-4.3)$ & 0.76 & \\
\hline \multirow[t]{3}{*}{ Tumour Stage (UBC) } & $\mathrm{pTa}$ & 77 & 31.4 & 10 & 22.7 & - & 0.276 \\
\hline & p T 1 & 86 & 35.1 & 14 & 31.8 & & \\
\hline & p T 2 & 83 & 33.5 & 20 & 45.5 & & \\
\hline \multirow[t]{2}{*}{ Muscle invasiveness (UBC) } & MIBC & 82 & 33.5 & 20 & 45.5 & $0.6(0.3-1.2)$ & 0.13 \\
\hline & NMIBC & 163 & 66.5 & 24 & 54.5 & & \\
\hline \multirow[t]{2}{*}{ Tumour Grade (UBC) } & High Grade & 131 & 53.5 & 25 & 56.8 & $0.9(0.5-1.7)$ & 0.68 \\
\hline & Low Grade & 114 & 46.5 & 19 & 43.2 & & \\
\hline \multicolumn{2}{|l|}{ pT1HG (Urothelial NMIBC) } & 48 & 29.4 & 7 & 29.2 & $1.0(0.4-2.6)$ & 0.977 \\
\hline \multicolumn{2}{|l|}{ Presence of LVI (UBC) } & 17 & 6.9 & 2 & 4.5 & $1.6(0.4-7.0)$ & 0.555 \\
\hline
\end{tabular}

CI: Confidence interval; UBC: Urothelial bladder cancer; NUBC: Non-urothelial bladder cancer; LVI: Lymphovascular invasion; MIBC: Muscle invasive bladder cancer; NMIBC: Non muscle invasive bladder cancer 


\section{Discussion}

Bladder cancer is the ninth commonest malignancy worldwide and $\mathrm{BC}$ ranks nineteenth in the female [11]. In a previous study, UBC accounted for $93.4 \%$ of primary BC in Sri Lanka [2]. In our cohort of patients with primary BC there was a male preponderance (male: female ratio of 4.7:1) similar to those in the West. There were differences in the clinical and histopathological characteristics of bladder cancer between the genders, where a higher proportion of female bladder cancers were NUBC, incidentally detected, solid and muscle invasive compared with males. NUBC in women constituted nearly $20 \%$ whereas in men it represented only $5.5 \%$ of patients. NUBC is considered a more aggressive form of $\mathrm{BC}$ compared with the more common UBC [12].

In our study, the mean age of women with UBC and NUBC were 67 and 62.5 years respectively. In a 7-year study of BC from Multan, Pakistan, there were 44 women of 204 patients with a median age of 55 years with the majority (88\%) presenting with haematuria. All women had UBC with 33 of 44 (75\%) having MIBC (T2-T4 disease). Furthermore, all women were non-smokers [13].

Visible haematuria was the commonest initial presentation encountered in $71 \%$ of women in the present study. Women are more likely to be diagnosed with urinary tract infection and receive 3 or more courses of antibiotics with longer delays between presentation with haematuria and diagnosis of $\mathrm{BC}$ than men [14]. Smoking was known to account for $50 \%$ and $31 \%$ of BCs in men and women respectively [15]. In a previous study from our urology unit, all women were never smokers [2].

The increase in incidence of bladder cancer in males could be explained by the differences in the exposure to risk factors. Cigarette smoking is the most important risk factor for bladder cancer [16, 17]. Secondly, occupational exposure in several industries including aromatic amines, cable, rubber and dyes are also important risk factors [18, 19]. The higher exposure of these risks factors in males could explain the increased incidence, however this does not explain the reason for the aggressive tumours that occur in female. Furthermore, some authors believe that the observed increase in incidence in males cannot be completely explained by the higher exposure to risk factors in males compared with females [20]. This is because the increased male preponderance remained similar, although the smoking habits and job exposure became quite similar among both sexes over time in industrialised countries [21]. Other factors such as anatomic or hormonal differences, and delay in presentation and diagnoses, may also affect the incidence and clinical behaviour between the gender [22, 23]. Thus further prospective studies are needed to study these variations in detail.

Studies have shown that a significantly greater proportion of women are diagnosed at an advanced stage compared with men [24, 25]. A large population based study of 5259 patients showed that women were more likely to have muscle-invasive disease at the time of cystectomy [26]. Analysis of all primary UBC patients reported to Swedish National Registry from 1997 to 2011 $(30,310$ patients) showed a greater proportion of women than men had muscle-invasive disease (stage T2-T4) at presentation (28.6\% vs $24.9 \%$, p <0.001) [27]. In the present study, although the age at presentation was similar for both sexes, a significantly higher proportion of bladder cancers were muscle invasive in females compared with males ( $53 \%$ vs. $34 \%, \mathrm{p}=0.009)$. Analysis of UBC subset also revealed a higher proportion of muscle invasive disease in females however it was not statistically significant ( $46 \%$ vs. $34 \%, \mathrm{p}=0.14$ ). Furthermore in a review paper, females were found to have more advanced tumors at the time of diagnosis [28]. Importantly in our study, a significantly higher proportion of females were incidentally diagnosed while evaluating for a non-related symptom ( $20 \%$ vs. $9 \%, \mathrm{p}=0.016)$. This may account for the delayed presentation or advanced disease at diagnosis.

There are several limitations in this study. We described the descriptive data for treated patients retrospectively and thus we could not perform further evaluation of the causes and risk factors of bladder cancer. A considerably high proportion were lost to follow up and thus, meaningful analysis related to outcome and survival between the two genders was not possible.

\section{Conclusions}

Primary BC in Sri Lankan women is unique. They have a significantly higher proportion of patients with NUBC and muscle invasive UBC-biologically more aggressive states, compared to men. Many factors may be responsible for these gender differences, including exogenous such as exposure to chemical carcinogens and smoking and endogenous such as hormonal factors. Thus, further prospective studies are needed to study this in detail.

\section{Acknowledgements}

None.

\section{Data availability}

All data generated and analyzed in this publication are from our database on bladder cancer prospectively maintained since the year 2002 electronically.

\section{Conflict of interests}

The authors declare that they have no competing interests. 


\section{References}

1. Ferlay J, Soerjomataram I, Dikshit R, et al. Cancer incidence and mortality worldwide: sources, methods and major patterns in GLOBOCAN 2012. Int J Cancer 2015; 136.

2. Goonewardena SAS, De Silva WAS, De Silva MVC. Bladder cancer in Sri Lanka: experience from a tertiary referral center. Int J Urol 2004; 11: 969-72.

3. Shariat SF, Sfakianos JP, Droller MJ, Karakiewicz PI, Meryn S, Bochner BH. The effect of age and gender on bladder cancer: a critical review of the literature. BJU Int 2010; 105: 300-8.

4. Fajkovic H, Halpern JA, Cha EK, et al. Impact of gender on bladder cancer incidence, staging, and prognosis. World J Urol 2011; 29: 457-63.

5. Najari BB, Rink M, Li PS et al. Sex disparities in cancer mortality: the risks of being a man in the United States. $J$ Urol 2013; 189: 1470-4.

6. Siegel RL, Miller KD, Jemal A. Cancer statistics, 2015. CA Cancer J Clin 2015; 65: 5-29.

7. Marks P, Soave A, Shariat SF, Fajkovic H, Fisch M, Rink M. Female with bladder cancer: what and why is there a difference? Translational Andrology and Urology 2016; 5: 668-82.

8. Micheli A, Mariotto A, Rossi AG, Gatta G, Muti P, Group EW. The prognostic role of gender in survival of adult cancer patients. Eur J Cancer 1998; 34: 2271-8.

9. Cheng L, MacLennan GT, Lopez-Beltran A. Histologic grading of urothelial carcinoma: a reappraisal. Hum Pathol 2012; 43: 2097-108.

10. Magers MJ, Lopez Beltran A, Montironi R, Williamson SR, Kaimakliotis HZ, Cheng L. Staging of bladder cancer. Histopathology 2019; 74: 112-34.

11. Antoni S, Ferlay J, Soerjomataram I, Znaor A, Jemal A, Bray F. Bladder cancer incidence and mortality: a global overview and recent trends. Eur Urol 2017; 71: 96-108.

12. Jayarajah U, Herath KB, Fernando MH et al. A clinicopathological study of non-urothelial bladder cancers in a cohort of patients from a tertiary care urology unit in Sri Lanka. Ceylon Med J 2018; 63: 92-4.

13. Rafique M. Clinico-pathological features of bladder carcinoma in women in Pakistan and smokeless tobacco as a possible risk factor. World J Surg Oncol 2005; 3: 53.

14. Cohn JA, Vekhter B, Lyttle C, Steinberg GD, Large MC. Sex disparities in diagnosis of bladder cancer after initial presentation with hematuria: a nationwide claims based investigation. Cancer 2014; 120: 555-61.
15. Wynder EL, Goldsmith R. The epidemiology of bladder cancer. A second look. Cancer 1977; 40: 1246-68.

16. Brennan $\mathrm{P}$, Bogillot $\mathrm{O}$, Greiser $\mathrm{E}$, et al. The contribution of cigarette smoking to bladder cancer in women (pooled European data). Cancer Causes Control 2001; 12: 411-7.

17. Brennan $\mathrm{P}$, Bogillot $\mathrm{O}$, Cordier S, et al. Cigarette smoking and bladder cancer in men: A pooled analysis of 11 case control studies. Int J Cancer 2000; 86: 289-94.

18. Olfert SM, Felknor SA, Delclos GL. An updated review of the literature: risk factors for bladder cancer with focus on occupational exposures. South Med J 2006; 99: 125664.

19. Mannetje At, Kogevinas M, Chang-Claude J, et al. Occupation and bladder cancer in European women. Cancer Causes Control 1999; 10: 209-17.

20. Hartge P, Harvey EB, Linehan WM et al. Unexplained excess risk of bladder cancer in men. JNCI: Journal of the National Cancer Institute 1990; 82: 1636-40.

21. Barbeau EM, Leavy-Sperounis A, Balbach E. Smoking, social class, and gender: what can public health learn from the tobacco industry about disparities in smoking? Tob Control 2004; 13: 115-20.

22. McGrath M, Michaud DS, De Vivo I. Hormonal and reproductive factors and the risk of bladder cancer in women. Am J Epidemiol 2005; 163: 236-44.

23. Cantwell MM, Lacey JV, Schairer C, Schatzkin A, Michaud DS. Reproductive factors, exogenous hormone use and bladder cancer risk in a prospective study. Int J Cancer 2006; 119: 2398-401.

24. Mungan NA, Kiemeney LA, van Dijck JA, van der Poel HG, Witjes JA. Gender differences in stage distribution of bladder cancer. Urology 2000; 55: 368-71.

25. Fleshner NE, Herr HW, Stewart AK, Murphy GP, Mettlin $\mathrm{C}$, Menck HR. The national cancer data base report on bladder carcinoma. Cancer 1996; 78: 1505-13.

26. Patafio FM, Robert Siemens D, Wei X, Booth CM. Is there a gender effect in bladder cancer? A population-based study of practice and outcomes. Canadian Urological Association Journal 2015; 9: 269-74.

27. Thorstenson A, Hagberg O, Ljungberg B, et al. Genderrelated differences in urothelial carcinoma of the bladder: a population-based study from the Swedish National Registry of Urinary Bladder Cancer. Scandinavian Journal of Urology 2016; 50: 292-7.

28. Dobruch J, Daneshmand S, Fisch M, et al. Gender and Bladder Cancer: A Collaborative Review of Etiology, Biology, and Outcomes. Eur Urol 2016; 69: 300-10. 